\title{
Abordagem discursiva de leitura de um vídeo digital
}

\author{
Luciana Cristina Ferreira Dias Di Raimo \\ Universidade Estadual de Maringá (UEM), Maringá, Paraná, Brasil \\ diaslucian@yahoo.com
}

DOI: http://dx.doi.org/10.21165/el.v46i3.1521

\begin{abstract}
Resumo
Neste artigo, apresento uma abordagem didática de leitura de cunho discursivo, com base em um vídeo informativo disponibilizado no sítio eletrônico da revista Veja intitulado "Exploradores urbanos". A proposta de leitura tem como objetivo apresentar possíveis encaminhamentos para a imagem em movimento, tendo em vista os conceitos: condições de produção, paráfrase, polissemia e a não transparência do dizer. $\mathrm{Na}$ prática de leitura implementada, vale destacar que o vídeo nos permitiu problematizar alguns aspectos relevantes ao ensino de leitura, dentre os quais: (i) as condições de produção e circulação de um vídeo cuja autoria está relacionada a uma agência e não à Veja; (ii) o investimento nas paráfrases visuais e no efeito metafórico (PÊCHEUX, 1975).
\end{abstract}

Palavras-chave: leitura discursiva; vídeos-digitais; paráfrase; polissemia.

\section{Discursive approach of reading concerned with a digital video}

\begin{abstract}
In this paper, I present a didactic approach of discursive reading based on an informational video available on the website of Veja magazine titled "Urban Explorers". This reading proposal aims to present possible referrals to the moving image, with a view of the concepts of production conditions, paraphrase, polysemy and the no transparency saying. In the implemented reading practice, it is worth mentioning the video allowed to problematize on some important aspects of the teaching of reading, among which: (i) the conditions of production and circulation of a video whose authorship is related to an agency and not to Veja; (ii) investment in visual paraphrases and metaphorical effect (PÊCHEUX, 1975).
\end{abstract}

Keywords: discursive reading; digital video; paraphrase; polysemy.

\section{Gestos iniciais}

A problemática da leitura da imagem em movimento em contexto de sala de aula é um ponto que nos chama a atenção na medida em que contemplar materialidades visuais pode favorecer um trabalho no espaço escolar a partir do qual "toda palavra é sempre parte de um discurso" (ORLANDI, 1999, p. 43), bem como encaminhar trajetos de leitura nos quais interessa ao professor e alunos(as) compreender como materiais simbólicos diferentes (cor, imagem, som) produzem certos efeitos e não outros, a partir de suas especificidades.

Sob um efeito de evidência, a imagem fixa ou a imagem em movimento emerge, na contemporaneidade, como materialidade que nos seduz, que nos atropela o tempo todo no uso das novas tecnologias de informação, sobretudo nas mídias sociais, na leitura de gêneros informativos, que nos instiga a parar o que estamos fazendo para pelo menos "passar os olhos". Somos consumidores de imagens em diversas práticas de 
linguagem - também fora da escola, assim como nos deparamos com o excesso do não verbal, como se a imagem fosse mero acréscimo ou ilustração. A imagem de modo contraditório é sempre o que "aparece". Diante do exposto, me pergunto: em que medida a imagem é também compreendida e não somente vista?

No caso específico deste estudo, interessa-me problematizar possibilidades de leitura da imagem, mais especificamente, da imagem em movimento em um vídeodigital disponibilizado no sítio eletrônico da revista Veja intitulado "Exploradores urbanos", em meio ao espaço da sala de aula. Como se trata de uma proposta de leitura voltada para um contexto de ação, meu propósito é o de discutir as possíveis contribuições da análise do discurso de linha francesa, doravante $\mathrm{AD}$, a partir de estudiosos como Orlandi (1999, 2001, 2006) e Pêcheux, $(1988,1990)$, tendo em vista a formulação e apresentação de uma proposta discursiva de leitura, levando-se em conta uma turma de $1^{\circ}$ ano do curso de Letras, mais especificamente, alunos da disciplina de Oficina de Leitura e produção de textos, com a qual já tenho familiaridade e experiência desde 2010.

A proposta tem como objetivo repensar e deslocar as possibilidades de abordagem do texto eletrônico, visto não somente como uma organização imagética ligada a um imaginário de inovação que também afeta o jornalismo. Graças à filiação à perspectiva discursiva, no lugar de me perguntar "o que o texto quis dizer", busquei trazer um novo olhar a partir do qual me interrogo a respeito de "como o vídeo-digital significa". Além disso, se o vídeo emerge como efeito de apresentação de um fato/acontecimento como se o sentido fosse único, transparente, a análise discursiva pode relativizar a evidência de uma única interpretação e abrir espaços para outras leituras também possíveis.

Considerando a necessidade de tomar o sentido como opaco, dividido e sempre relacionado a posições em jogo, em uma dada conjuntura sócio-histórica, o artigo apresenta duas partes: na primeira, dirijo o foco para as bases teóricas sobre as quais se assenta nossa proposta de leitura pensada em um processo de ensino-aprendizagem da língua portuguesa especificamente, dentro do contexto de uma turma de primeiro ano do curso de Letras e, na segunda parte, apresento propostas de leitura do vídeo "Exploradores urbanos", buscando trabalhar na tensão entre uma unidade imaginária de leitura (a evidência de um único sentido) e a polissemia (possibilidades de outras leituras para as formulações visuais).

\section{Análise do discurso: ancoragem teórica}

Num primeiro momento, formular uma proposta de leitura me exigiu problematizar em que medida o ensino de língua materna pode estabelecer relações com as contribuições epistemológicas da análise do discurso, o que me levou a tomar a sala de aula como um "espaço de movimentos de sentidos" (BOLOGNINI; PFEIFFER; LAGAZZI, 2009, p. 7). Além disso, é preciso problematizar o "caráter fluido da linguagem", trazendo à tona possibilidades de deslocamento que as diferentes formas significantes trazem.

Ora, se os estudos mais atuais sobre o ensino reiteram a necessidade de uma abordagem dos fatos/práticas de linguagem em contextos reais, a $\mathrm{AD}$ parece comungar 
com um olhar para o funcionamento do discurso, o trabalho dos sentidos no texto e as subjetividades em jogo, seja na sala de aula, seja na instituição escolar.

Dessa forma, na medida em que a visão discursiva de leitura envolve um processo de elucubrações de ordem teórico-metodológica, o que contribui para que a leitura seja vista como um processo discursivo e não como mero gesto de decodificação, este diálogo entre a $\mathrm{AD}$ e a leitura foi um momento inaugural dos pontos de convergência entre tais campos, o que permitiu o desenvolvimento de pesquisas e produção sobre a temática.

Podemos dizer que o sujeito da análise do discurso é duplamente afetado: de um lado, considerando-se seu funcionamento psíquico, o sujeito é falado pelo inconsciente, parte que ele desconhece; de outro, considerando-se seu funcionamento social, o sujeito é afetado pela ideologia, já que não há discurso sem sujeito, nem sujeito sem ideologia. Nos termos de Pêcheux (1988, p. 133-134), "o recalque inconsciente e o assujeitamento ideológico estão materialmente ligados, sem estar confundidos, no interior do que se poderia designar como o processo do Significante na interpelação e na identificação".

Neste caso, é preciso considerar, de um ponto de vista discursivo, que o sentido não está preso às palavras, mas precisa ser tomado a partir das posições em jogo em uma dada conjuntura ou da inscrição do dizer em uma dada formação discursiva.

Em termos de definição, a formação discursiva se coloca como "o que pode e deve ser dito (articulado sob a forma de uma arenga, um sermão, um panfleto, uma exposição, um programa etc.) a partir de uma posição dada numa conjuntura" (PÊCHEUX; FUCHS, 1997, p. 166). Segundo Pêcheux (1988), o sentido de uma palavra, expressão ou proposição não existe "em si mesmo", mas é determinado pelas posições ideológicas que estão em jogo no processo sócio-histórico no qual as palavras, expressões e proposições são produzidas. Assim, "as palavras, expressões, proposições etc., mudam de sentido segundo as posições sustentadas por aqueles que as empregam" (PÊCHEUX, 1988, p. 160).

Em termos de constituição do sentido, entendo que é preciso mobilizar, na prática de leitura, as condições materiais de base, como diria Pêcheux (1988, p. 91), que são linguísticas e também históricas. Segundo o autor:

[...] o sistema da língua é, de fato, o mesmo para o materialista e para o idealista, para o revolucionário e para o reacionário, para aquele que dispõe do conhecimento dado e para aquele que não dispõe desse conhecimento. Entretanto, não se pode concluir, a partir disso, que esses diversos personagens tenham o mesmo discurso: a língua se apresenta, assim, como a base comum dos processos discursivos diferenciados, que estão compreendidos nela na medida em que, como mostramos mais acima, os processos ideológicos simulam os processos científicos.

De um lado, temos a base linguística, e, de outro, os processos discursivos que se materializam na língua. Tais processos discursivos dizem respeito às possibilidades de substituição, paráfrases, relações de sinonímia que funcionam entre os elementos de uma dada formação discursiva, dentro de condições de produção dadas. 
O conjunto dessas formações discursivas acaba por formar um complexo dominante, o interdiscurso, tomado como "todo o conjunto de formulações feitas e já esquecidas que determinam o que dizemos" (ORLANDI, 1999, p. 33).

Ao considerarmos a base sobre a qual o discurso se materializa, e os processos discursivos, uma distinção conceitual fundamental diz respeito aos conceitos de intra e interdiscurso. O nível intradiscursivo de análise, isto é, o eixo da formulação, é compreendido como a sequência efetivamente produzida na horizontalidade da cadeia verbal (SERRANI, 2005). É a dimensão que enfoca o começo, meio e fim de um texto, ou, segundo Orlandi (1999, p. 33), "aquilo que estamos dizendo naquele momento dado, em condições dadas". Já o nível do interdiscurso, o da constituição dos sentidos, corresponde à dimensão vertical da linguagem, isto é, à relação de um enunciado com uma rede de dizeres já-ditos e esquecidos. Com efeito, é válido considerar que o interdiscurso determina o intradiscurso. Trata-se do intradiscurso enquanto fio do dizer, linearização, a dimensão horizontal do discurso, ou ainda, atualidade. Se a formulação é constituída pela memória, ela é também atualização dessa memória. Segundo Orlandi (1999, p. 33), "é desse jogo que tiram seus sentidos".

No que se refere à memória discursiva, não se trata de considerá-la como memória psicológica ligada a um conjunto de fatos lembrados e guardados. A memória discursiva é condição para que a interpretação se produza. Dito de outra forma, trata-se do "saber discursivo que torna possível todo dizer e que retorna sobre a forma do préconstruído, o já-dito que está na base do dizível, sustentando cada tomada de palavra". (ORLANDI, 1999, p. 31)

Mas se repetimos sentidos exteriores e anteriores, a língua também falha, ou seja, é aberta ao equívoco - à possibilidade de o sentido ser outro. Nesse caso, invisto no questionamento proposto pela $\mathrm{AD}$ relativo à ilusão do sentido literal e único. Pêcheux (1990), a partir de uma análise do enunciado "Ganhamos (On a gagné)", proferido em meio à vitória de François Mitterand, na França, em maio de 1981, mostra a importância de perguntar pelos sentidos, em suas condições de produção, de colocar, como analistas, as interpretações em suspenso. Na medida em que "Ganhamos" é um enunciado opaco, é preciso nos interrogar sobre: quem ganhou? Ganhou o quê? Quem compõe o conjunto do "nós" (ganhamos)? São perguntas que apontam para a polissemia das palavras e para a equivocidade do dizer.

Estou considerando que o equívoco não é visto como erro, como prega o senso comum. O equívoco é constitutivo da linguagem e diz respeito ao fato de que "as palavras em funcionamento são passíveis de sentidos contraditórios, de diferentes interpretações" (LAGAZZI-RODRIGUES, 2006, p. 84). Ainda vale afirmar, me apoiando em Orlandi (1999, p. 53), que "se o sentido e o sujeito poderiam ser os mesmos, no entanto, escorregam, derivam para outros sentidos, para outras posições". Eis alguns conceitos-chave que servirão de ponto de sustentação da proposta que ora se configura. 


\section{Proposta discursiva de leitura de um vídeo-digital}

Uma vez que a linguagem funciona sob o modo da textualidade, pretendo, nesta seção do artigo, estabelecer conexões entre a formulação do vídeo-digital em sua dimensão pragmática, com uma unidade, progressão (efeito texto), relacionado ao nível do intradiscurso e o interdiscurso (memória), com o propósito de apresentar uma abordagem didática de um vídeo digital.

$\mathrm{Na}$ perspectiva discursiva, ler um texto não se restringe a uma série de estratégias (ler as informações gerais e partir para as específicas), buscando apreender o que o texto quis dizer. Ler é entender como o texto diz e não o que ele diz, isto é, como o texto produz sentidos. Além disso, ler significa saber que tanto o sentido pode ser outro quanto o sujeito não tem controle pleno dos sentidos. É entender que a linguagem serve para comunicar e para não comunicar (ORLANDI, 1999, p. 21).

Em meio a tais reflexões propostas por Orlandi, um ponto que me chama a atenção diz respeito ao fato de que, diante de qualquer objeto simbólico, o sujeito é levado a dizer: o que isso significa? Tal olhar da AD dirigido para aulas de leitura pode abrir espaços para que abordagens de textualidades diversas tenham, como pano de fundo, discussões sobre a linguagem como um ritual com falhas (PÊCHEUX, 1990), ou seja, em meio ao funcionamento da linguagem, há que se pensar na possibilidade de advirem outros sentidos, a partir de posições discursivas várias.

Neste caso, vale citar as três premissas de Orlandi (2006, p. 12), que, a meu ver, representam, em termos de concepções de linguagem e de sujeito, pontos de convergência entre AD e estudos aplicados, a partir da (im)possibilidade de se pensar: (i) um autor onipotente cujas intenções controlassem todo o processo de significação; (ii) a transparência do texto que diria por si só uma significação e (iii) um leitor onisciente que dominasse as múltiplas determinações dos sentidos que se jogam em um processo de leitura.

Inspirando-me em Fernandes (2013, p. 227), acredito que "o uso de textos visuais em atividades escolares de leitura e escrita impulsiona a instauração da autoria por parte do sujeito-aluno". Em outras palavras, defendo que a escola deva permitir ao aluno entrar em processo no qual se dá a assunção, por parte do sujeito, de seu papel de autor. Nas palavras de Orlandi (2006, p. 106), "essa assunção implica, segundo o que estamos procurando mostrar, uma inserção (construção) do sujeito na cultura, uma posição dele no contexto histórico social".

Por questões de tempo e para que a abordagem não fique superficial, serão apresentados apontamentos concernentes a um único vídeo, no sentido de problematizar as possibilidades de implementar uma abordagem discursiva de sua textualidade envolvendo as condições de produção, a materialidade linguística, até atingirmos o processo de produção de sentidos. Estou me inspirando em propostas de análises prépedagógicas empreendidas por Serrani (2003) e Baghin-Spinelli (1998), cuja finalidade foi a de apresentar um caminho possível de abordagem discursiva do texto. 


\section{Condições de produção e circulação do vídeo-digital}

O vídeo "Exploradores urbanos" circulou na página da revista Veja a partir de 05 de abril de 2014 e constituiu a editoria "Mundo". O vídeo é referente à agência de notícias Agence France-Presse (AFP), considerada uma das principais agências de notícias do mundo, cuja especialidade é a de fornecer informação rápida sobre a atualidade internacional em texto, foto, vídeo, gráfico e videográfico para diversos veículos de comunicação, como revistas, jornais, sites. A agência AFP cobre diversos temas, tais como: política, economia, conflitos, cultura, esporte, meio ambiente, tecnologia e saúde. Ainda é possível acessar o vídeo por meio do link $<$ http://veja.abril.com.br/multimidia/video/exploradores-urbanos $>$, a partir do canal de vídeos Youtube, na página $<$ https://www.youtube.com/watch?v=FzzxlvuUjeE $>$.

Tendo em vista os encaminhamentos para uma abordagem didática do vídeo em tela, primeiramente, do ponto de vista teórico, uma questão nodal que me chama atenção diz respeito às condições de produção e de formulação do vídeo publicado em uma página eletrônica e um canal de vídeo entendidos como espaços de circulação de sentidos. Assim sendo, segundo Orlandi (2006, p. 30), "as condições de produção incluem pois os sujeitos e a situação" e podem ser tomadas em seu sentido estrito (o que corresponde às circunstâncias de enunciação específicas da formulação do vídeo) e sentido lato (o que corresponde ao contexto sócio-histórico, mais amplo).

Tomando como base as palavras de Orlandi (2001, p. 9), "formular é dar corpo aos sentidos". Conforme Lagazzi (2011, p. 499), "no caso de um texto alocado no espaço digital, importam também os links, muitas vezes o movimento de imagens, a sonoridade e a musicalidade, em caso de vídeos". Dessa forma, a materialidade específica de vídeos-digitais, em práticas de leitura em sala de aula de língua materna, consequentemente, requer que pensemos na imbricação entre texto verbal, sonoro e imagético (envolvendo diferentes formas materiais significantes: grafia, desenho, fotografia, cor) e na produção de movimentos, animação, no que diz respeito à produção dos sentidos.

É interessante discutir em que medida o vídeo produzido por uma agência é trazido pela revista Veja como material a ser lido e consumido em sua versão eletrônica. Temos um gesto no qual a revista coloca em cena um material produzido por outro veículo de comunicação, uma agência internacional legitimada em produzir sentidos sobre temáticas ligadas a países estrangeiros, cujo logotipo está exposto na parte inferior do vídeo, atestando um efeito-autoria autorizado a partir de uma posição-jornalista externa à revista Veja. Considerando as condições de produção do vídeo, apresentamos, como primeiro momento da abordagem, as interrogações de ordem discursiva, que se seguem:

1. A leitura de vídeos no ciberespaço é uma prática comum em sua vida?

2. Tente responder: Quem enuncia? Para quem? Onde o vídeo circula? Que papel tem a agência AFP na produção de um efeito-verdade no vídeo?

3. Você já leu/viu imagens/textos de exploradores urbanos? Se não, faça uma pesquisa/busca por imagens na internet. Que sentidos você atribui a essa prática? 
Neste momento inicial da abordagem do vídeo-digital, julguei relevante trabalhar com os sujeitos-alunos suas histórias de leitura, isto é, tomar por base tudo que o sujeito leu e viu a respeito da prática da exploração urbana ou de outras práticas de exploração que jogam com sentidos de aventura, adrenalina e busca por paz. Uma vez que as histórias de leitura dos alunos constituem o sujeito-leitor, ideológica e socialmente, e vão permitir que o texto seja visto como espaço aberto à significação, um exercício produtivo é o de investir em um trabalho com formulações visuais já-vistas que vêm carregadas de sentidos anteriores que constituem trajetos de leituras dos alunos com base no vídeo-digital.

\section{Relações entre as regularidades nas formulações visuais e os deslizes de sentidos}

Meu propósito é o de analisar, no jogo entre o mesmo e o diferente, a reprodução do estabilizado (evidência de um sentido único) no vídeo "Exploradores urbanos" e os possíveis deslizamentos de sentido, ainda que o texto jornalístico - vídeo - esteja sob a ilusão da eficácia da informação, calcado em um sujeito pragmático que controla $o$ modo de produção dos sentidos.

Meu gesto analítico inicial, empreendido em uma análise prévia à leitura (SERRANI, 2005), foi o de trabalhar em meio ao procedimento parafrástico, nos termos de Lagazzi (2015), dando consequências às paráfrases visuais e às derivas de sentidos de fotogramas ${ }^{1}$.

Em termos de paráfrases nas formulações visuais, considerei os fotogramas que seguem abaixo, tomando-se por base a discursivização sobre os exploradores urbanos no vídeo de Veja: as imagens em relação de paráfrase trazem como regularidades cenas do(a) explorador urbano em que se textualizam seu corpo e seu entorno.

\section{Fotograma 1}

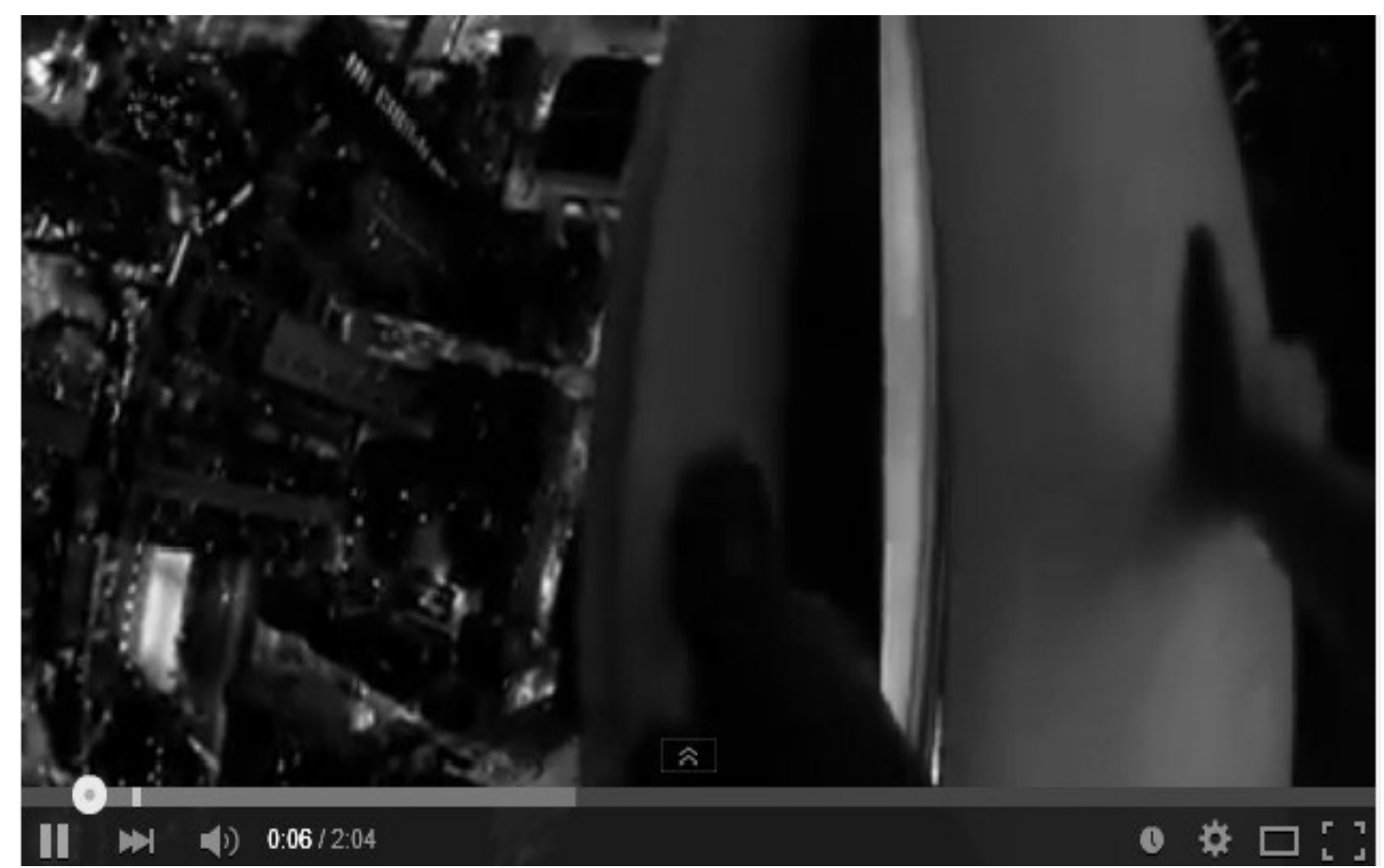

\footnotetext{
${ }^{1}$ Fotogramas estão sendo entendidos neste trabalho com frames ou quadros de um material audiovisual.
} 
Fotograma 2

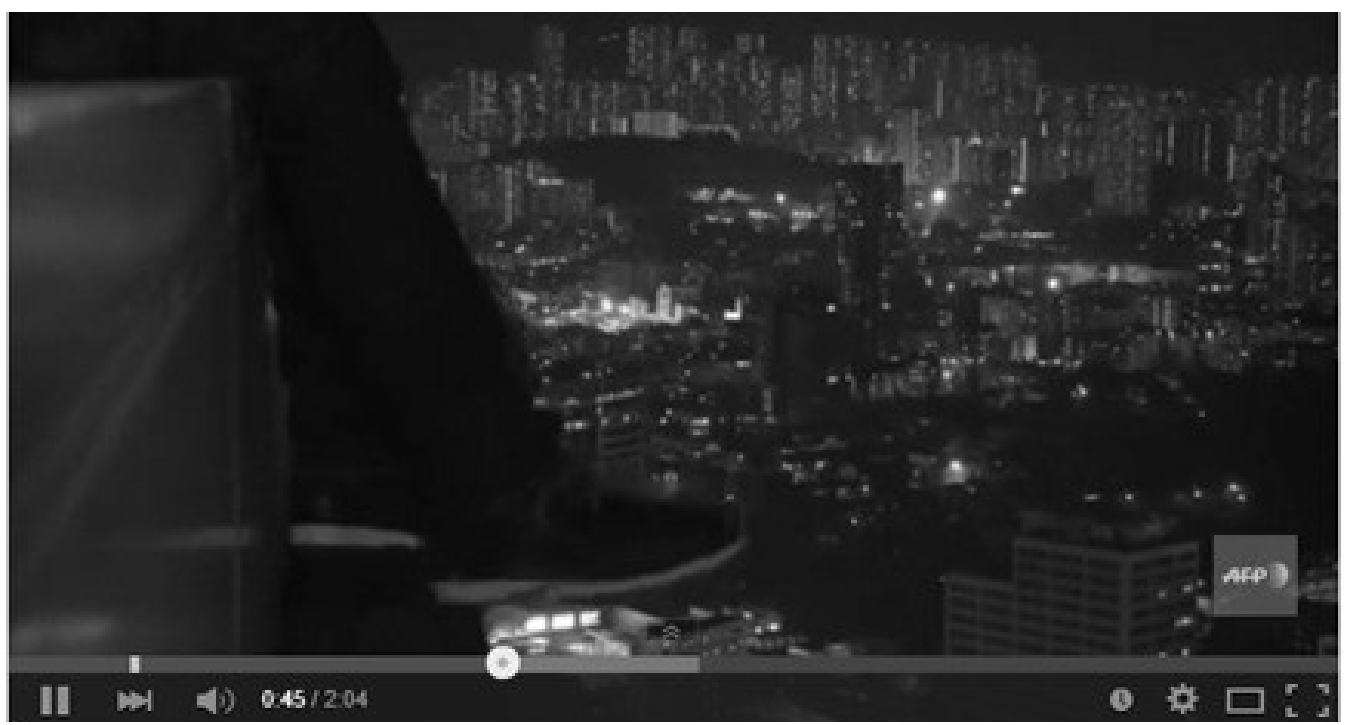

Fotograma 3

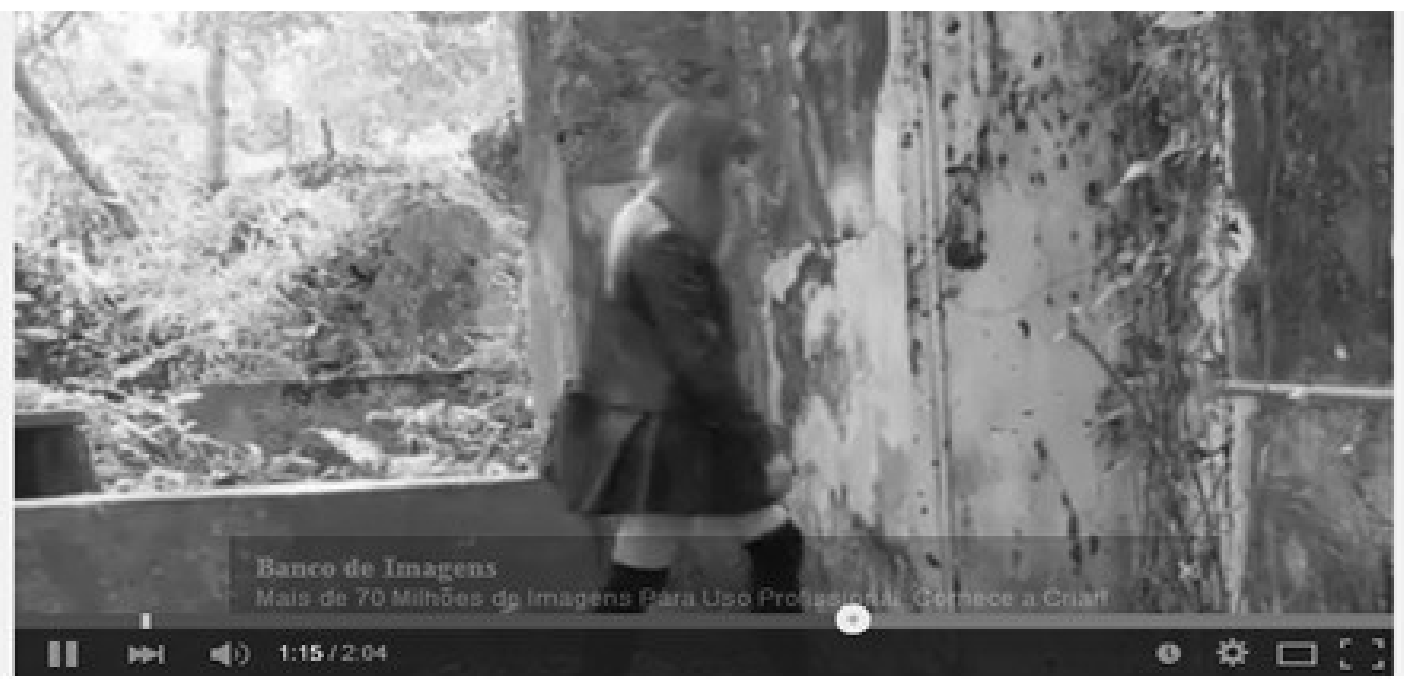

Fotograma 4

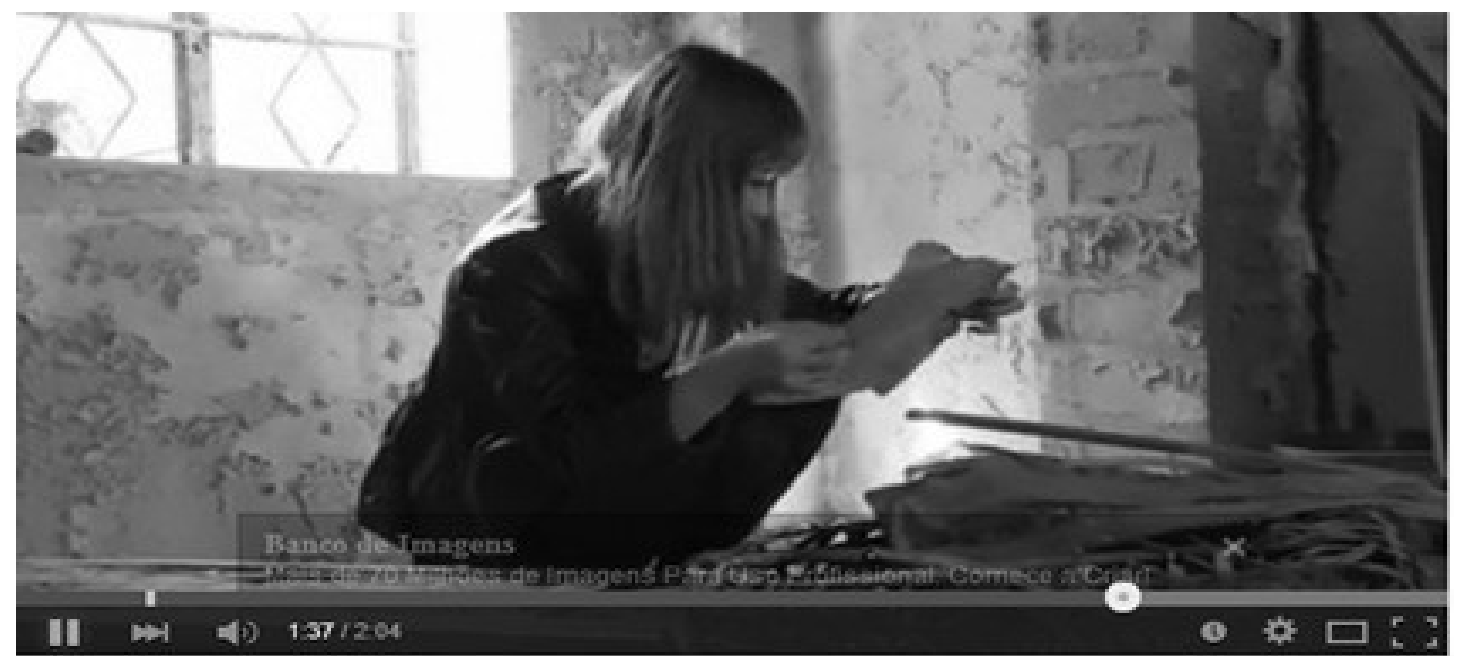


Notei que, considerando a formulação visual na composição de imagens em movimento, a discursivização sobre os exploradores urbanos, tomando a relação corpo e entorno, aponta para uma polissemia relativa à prática da exploração urbana: escalação de prédios, busca pela paz/tranquilidade distante do caos urbano, a busca/pesquisa por lugares esquecidos, abandonados.

Nesse caso, nos quatro fotogramas selecionados, tomando-se por base as regularidades, os dois primeiros fotogramas textualizam o corpo do explorador urbano na relação com o alto do prédio. Seja caminhando, seja sentado no seu topo, seja explorando locais esquecidos e em ruínas, os sentidos apontam para uma representação de exploração como prática que contempla o novo, o risco, a adrenalina, a aventura, a curiosidade, o gosto pela História, o interesse na pesquisa.

É possível também considerar uma relação de metonímia que marca os efeitos de sentidos produzidos pelo texto verbal e pela imagem. O topo do arranha-céu (parte com a qual o sujeito se relaciona) está em uma relação com a cidade (o todo) ou a construção antiga, esquecida é parte do desenvolvimento da cidade, é o que ficou de fora, jogando com sentidos em tensão: a paz buscada (ligada ao alto do prédio ou ao abandono da vila esquecida e sem habitantes) e o sufoco/densidade (ligado ao espaço urbano).

Uma regularidade presente no vídeo diz respeito a uma busca por paz e isolamento, na prática da exploração urbana. Seja na formulação da imagem do jovem Jonathan Tsang, cujo corpo aparece de costas para a câmera, contemplando a cidade do alto e sentado à beira de um prédio, seja na imagem da exploradora Airin percorrendo construções antigas e abandonadas, o isolamento e a tranquilidade, sob um efeito de evidência, são sensações e experiências buscadas nessa prática.

Assim, a visão da cidade que se formula no vídeo materializa um olhar de quem a contempla do alto, a partir de uma posição solitária e tranquila. Em diferentes ângulos, e a partir de zooms variados, a cidade de Hong Kong e seus prédios são textualizados, a partir do alto, e a imagem solitária do explorador urbano se contrapõe à população numerosa da cidade. Nesse caso, notamos o funcionamento da contradição em meio à produção de sentidos no vídeo: explorar a cidade é não explorar a cidade, mas seu céu, seus prédios e desfrutar uma solidão, um isolamento. $\mathrm{O}$ telhado/o alto dos edifícios é tomado como lugar da tranquilidade, de busca de paz em meio ao caos urbano.

Assim, a câmera não filma a cidade, mas formula imagens do alto dos prédios de onde a cidade pode ser vista de uma certa distância, de um outro ângulo. Sob um efeito de evidência, a imagem do jovem balançando os pés calmamente e sentado no alto de um prédio é desconcertante. Mas é preciso ir além das evidências e tentar compreender em que medida o vídeo dá corpo a imagens nas quais a exploração silencia sentidos inscritos da memória que ligam a atividade ao risco, ao perigo. A naturalidade do gesto apaga sentidos indesejáveis de que estar no alto do prédio também pode ser perigoso, arriscado, ou formas de driblar a segurança dos locais explorados, o que sugere o desrespeito a regras e normas ligadas a espaços, lugares e instituições.

As imagens do corpo de um jovem tranquilo, no alto do prédio, deslizam para a formulação de uma nova cena: a imagem de uma jovem explorando ruínas, construções antigas e pesquisando em meio a documentos em uma vila abandonada. Com efeito, podemos notar o deslizamento dos sentidos com base no efeito metafórico. Da 
exploração de arranha-céus empreendida por um corpo que se relaciona com a altura, de forma espontânea e tão natural, o sentido migra para outra possibilidade de exploração: de vilas (lugares) abandonadas e esquecidas.

Com efeito, nestes instantes finais do material, o vídeo deixa de focar os arranha-céus para dar destaque à experiência de uma jovem, Airin T, com a exploração de vilas abandonadas. Diferentemente das imagens anteriores, a prática da exploração urbana - que envolve no vídeo não mais um esporte radical de escalar prédios - mas a prática da investigação de construções antigas, documentos e monumentos - ruínas em meio a um ambiente bucólico permeado por uma paisagem mais próxima do rural.

Assim sendo, as composições visuais que materializavam o céu da cidade e seus prédios formulam sentidos ligados à história, à pesquisa investigativa, a partir da exploração de vilas esquecidas que estão fora do espaço da cidade. A vila é ao mesmo tempo uma parte que ainda resta e o que ficou de fora do movimento e desenvolvimento das cidades.

Tomando como base a memória (que compreende uma rede de imagens já formuladas anteriormente e esquecidas) relativa a diversas práticas de exploração (não somente a urbana), que sustenta a possibilidade de formulações visuais constitutivas do vídeo-digital, justamente sob a evidência de que explorar um lugar é "estar nele", pude contemplar, nesse caso, o funcionamento da contradição que instaura uma tensão: os exploradores urbanos são aqueles que (não) exploram a cidade: ou estão nos céus, no alto dos prédios ou em lugares abandonados.

Julgo relevante, no trabalho em sala de aula, investir justamente na opacidade da imagem que está relacionada a uma rede de imagens já vistas e que estão inscritas na memória. Compreendo, em sintonia com Courtine (1981), que as imagens mobilizadas na leitura constituem uma "rede de formulações" já significadas em uma formação discursiva dada. Assim sendo, ao contemplar imagens da escalação de altos prédios ou da exploração de ruínas, lugares distantes e de difícil acesso, em virtude de se tratar de um assunto pouco conhecido de grande parte dos leitores, acredito na possibilidade de considerar, na leitura, a polissemia como elemento produtivo: a que imagens já vistas o sujeito-leitor pode associar as imagens do vídeo - a cenas ligadas a esportes radicais, a fotografias de locais capturados por exploradores que se arriscam para ter o melhor ângulo, a imagens de ruínas e lugares ermos e esquecidos?

$\mathrm{Na}$ proposta de leitura ora apresentada, acredito que vale a pena observar o modo como formulações visuais do vídeo já vêm carregadas de sentidos anteriores dos quais o sujeito-leitor não escapa, tampouco tem controle da forma como tais sentidos o afetam. A depender dessa história de leitura de imagens de aventura, exploração, adrenalina, os sentidos podem suscitar uma pluralidade de leituras. Como observa Indursky (2010, p. 171), "se o texto é produzido sob determinadas condições de produção, a leitura também é feita a partir das condições de produção do leitor".

Com efeito, o próprio sentido de aventura aqui precisa ser considerado em sua dimensão polissêmica: que leituras possíveis podem ser feitas das imagens do sujeito sentado no alto do prédio ou de uma jovem vasculhando documentos em uma vila abandonada? 
Tendo como base a interdependência entre intradiscurso (formulação do vídeo, a partir do arranjo de imagens) e o interdiscurso que constitui e sustenta os sentidos (possíveis de serem formulados por meio de imagens), a partir de repetições, retomadas, esquecimentos e silenciamentos, julguei interessante produzir uma análise prévia à leitura deste material e considerar as possibilidades de trabalho discursivo com a leitura da imagem em movimento, permitindo a escuta de outros sentidos, fazendo valer a opacidade do dizer. Considerando outras possibilidades de discursivização da exploração urbana, tal prática implica outros sentidos que podem ser levantados e que não foram trabalhados nas imagens do vídeo disponibilizado no site de Veja: a busca por um ângulo único e singular na fotografia, a invasão de locais sem autorização prévia, acesso a lugares proibidos e arriscados (sistemas de esgoto, usinas desativadas, construções que apresentam riscos de desabamento) e a intervenção da polícia, cujo papel naturalizado é o de garantir a ordem, a não depredação de prédios ou vandalismo. Aquilo que poderia ter sido formulado visualmente e não foi constitui famílias parafrásticas visuais que estão em relação com os sentidos no vídeo.

1) Quais outras possibilidades de exploração urbana o vídeo poderia ter formulado em termos de imagem?

2) Quais leituras podem ser realizadas de um jovem caminhando no alto de um prédio?

3) A que redes de formulações visuais já vistas você remete as cenas do vídeo digital em tela?

\section{Gesto final}

Numa tentativa de trazer para a cena, sem a pretensão de esgotar o tema, as possibilidades de implementação de uma proposta de base discursiva para a sala de aula, entendo que esses diálogos entre os princípios e procedimentos da análise do discurso e questões ligadas ao ensino de língua materna produzem deslocamentos tanto nos cruzamentos de questões teóricas a serem problematizadas pelo professor quanto na abordagem prática da leitura de formulações visuais de um vídeo-digital.

Primeiro, acredito na relevância de uma abordagem discursiva, neste caso de materialidades audiovisuais, visto que a análise do discurso permite considerar a não transparência do dizer e a possibilidade de o sentido deslizar como ingredientes necessários na aula de leitura, entendendo esse contexto como lugar de movimentação de sentidos.

Diante de toda a complexidade de práticas escolares reais e contextualizadas, escolhi focalizar algumas questões que devem iluminar práticas de leitura da imagem, neste caso, em movimento, ancoradas na análise do discurso: (a) as práticas de linguagem não devem se restringir somente à materialidade imagética do texto, mas precisam contar com a análise do processo discursivo, da memória, do já-dito; (b) as práticas de linguagem não devem se limitar ao explícito, ao dito unicamente, mas podem sim problematizar o implícito, o que não foi dito e poderia ter sido, mas que significa ali naquela dada situação. 
Obviamente, as atividades sugeridas são algumas dentre outras que poderiam também ter sido pensadas, no caso do vídeo aqui contemplado. Com efeito, procurei não somente explorar a dimensão linguística na abordagem do texto, como também mobilizar questões ligadas à memória e às condições de produção do vídeo-digital sob análise, o que pode representar para o ensino de língua materna, neste caso especificamente para práticas escolares de leitura, novas possibilidades de abordagem do texto, um novo olhar para a linguagem compreendida como aberta e polissêmica.

\section{REFERÊNCIAS}

BAGHIN-SPINELLI, D. C. Uma proposta discursiva de leitura nos cursos de formação de professores de língua inglesa. In: SERRANI, S. (Org.). Fragmentos. Florianópolis: Ed. da UFSC, 2002. p. 79-100.

BOLOGNINI, C. Z.; PFEIFFER, C.; LAGAZZI, S. Discurso e Ensino: práticas de linguagem na escola. Campinas: Mercado das Letras, 2009.

COURTINE, J. Analyse du discours politique. Languages, 62, Paris, Larousse, 1981.

FERNANDES, C. A resistência da imagem. Uma análise discursiva dos processos de leitura e escrita de textos visuais. 2013. 225 f. Tese (Doutorado em Letras) - Instituto de Letra, Universidade Federal do Rio Grande do Sul, Porto Alegre, 2013.

INDURSKY, F. Estudos da linguagem: a leitura sob diferentes olhares teóricos. In: TFOUNI, L. V. (Org.). Letramento, escrita e leitura: questões contemporâneas. Campinas: Mercado de Letras, 2010. p. 163-178.

PÊCHEUX, M. Semântica e Discurso. Uma Crítica à Afirmação do Óbvio. Tradução de Eni P. de Orlandi et al. Campinas: Editora da UNICAMP, 1988 [1975].

PÊCHEUX, M. O discurso: estrutura ou acontecimento. Tradução de Eni Pulcinelli Orlandi. Campinas: Pontes, 1990.

PÊCHEUX, M.; FUCHS, C. A propósito da Análise Automática do Discurso: atualização e perspectivas. Tradução de Péricles Cunha. In: GADET, F.; HAK, T. (Org.). Por uma análise automática do discurso: uma introdução à obra de Michel Pêcheux. 3. ed. Campinas: UNICAMP, 1997 [1975]. p. 163-252.

ORLANDI, E. Análise de discurso. In: ORLANDI, E. P.; LAGAZZI-RODRIGUES, S. (Org.). Discurso e textualidade. v. 1. Campinas: Pontes, 2006. p. 13-31. . Análise do discurso. Princípios e procedimentos. Campinas: Pontes, 1999.

. Discurso e Leitura. 9. ed. São Paulo/Campinas: Cortez/Editora da UNICAMP, 2006.

LAGAZZI, S. M. Paráfrases da Imagem e Cenas Prototípicas: em torno da memória e do equívoco. In: FLORES, G.; NECKEL, N.; GALLO, S. (Org.). Análise de Discurso em Rede: Cultura e Mídia. v. 1. Campinas: Pontes, 2015. p. 177-189.

LAGAZZI, S. M. A equivocidade na circulação do conhecimento científico. Linguagem em (dis)curso, Tubarão, v. 11, n. 3, p. 497-514, dez. 2011. 
LAGAZZI-RODRIGUES, S. M. Texto e Autoria. In: ORLANDI, E. P.; LAGAZZIRODRIGUES, S. (Org.). Discurso e textualidade. v. 1. Campinas: Pontes, 2006. p. 81104.

SERRANI, S. Memórias discursivas, línguas e identidades sócio-culturais. Organon, Porto Alegre, v. 17, n. 35, p. 283-298.

Discurso e cultura na aula de línguas: Currículo - Leitura - Escrita.

Campinas: Pontes, 2005.

Recebido em: 11/08/2016

Aprovado em: 01/08/2017 